\section{Maxillofacial surgeons see a rise in violent crime}

A rise in violent crime has been seen by maxillofacial surgeons who have raised their concerns about the growing problem in advance of a summit on knife crime.

A new study ${ }^{1}$ published in The Surgeon journal was carried out by maxillofacial surgeons at King's College Hospital $(\mathrm{KCH})$ in south London.

The authors found that in just one year, 478 patients with penetrating trauma injuries were treated in the ED (emergency department) - the highest number since comparable records began in 2010, when just 172 patients were recorded, and up almost $20 \%$ since the year before.

The KCH study authors, Consultant Oral and Maxillofacial Surgeon (OMFS) Kathy Fan, Maxillofacial Surgery Trainee James Olding and Lead Trauma Nurse Carole Olding, wanted to understand what was behind the dramatic rise in violent knife crime injury in south London.

They collected data on all patients who attended the hospital ED with penetrating trauma to the head and neck over a one-year period (2016-17).

Of the 478 patients the hospital treated, 65 had penetrating trauma that involved the head or neck and the majority (82\%) were male.

The team found that interpersonal violence (IPV) caused the majority of injuries (54 cases or $83 \%$ ) they treated that included assault with knives, glass and firearms.

The IPV group had an average age of 25 , although the ages ranged from 13 to 70 . Half of the injuries happened locally to King's in the boroughs of Lambeth and Southwark.

Results of the study highlighted the diverse demographic mix affected by knife crime, and a wide range of weapons used that included kitchen knives, nail guns, bottles, and even a samurai sword.

While young males made up the vast majority of patients seen in at King's, there was also a growing number of young women as well as a number of patients from older age groups, up to age 71

The findings were revealed as Prime Minister Theresa May held a major summit in London on 1 April 2019 on knife crime, at which experts and community leaders met at Downing Street to explore ways to tackle the problem.

Report author James Olding said: 'Working on-call and overnight in OMFS in one of London's busiest trauma centres, I see more and more patients affected by violent trauma, including knife injuries. Traumatic injuries to the face are particularly devastating, both physically and psychologically. The face is socially the most important and visible part of the body.

Senior author, Consultant Oral and Maxillofacial Surgeon Kathy Fan, added: 'It is important to understand the cycle of violence and how to intervene in order to break the cycle, protect children and vulnerable adults, and prevent morbidity and mortality from such crime and violence'.

\section{References}

1. Olding J, Olding C, Bew D, Fan K. Penetrating head \& neck trauma - Epidemiology and injury characteristics in terror-related violence, interpersonal violence and deliberate self-harm at a level 1 trauma centre. Surgeon 2019; DOI: 10.1016/j.surge.2019.01.001.

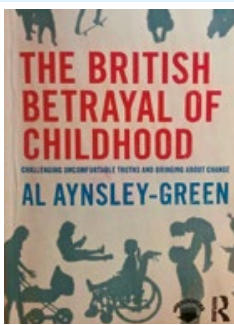

\section{THE BRITISH BETRAYAL OF CHILDHOOD: CHALLENGING UNCOMFORTABLE TRUTHS AND BRINGING ABOUT CHANGE}

Al Aynsley-Green;

2018; Routledge; price $£ 13.99$ pp. 272;

ISBN: 9781138297913 :

That there is a problem with children's oral health is well documented. The scale of it, for what is an almost entirely preventable disease, is a national disgrace. The profession has consistently argued that something needs to be done, not least the specialist society dedicated to improving the oral health of children in the UK. Progress, however, remains lamentable. Why is this the case? Anyone seeking an answer, and having an interest in addressing the problems, should read Aynsley-Green's exceptional book.

The author highlights the 'scandal' is not just limited to oral health; it is one of childhood and societal attitudes. Outcomes for general health, education, social care, youth justice and poverty are all discussed and present an equally damning indictment of the failures of policy and politicians in the UK. As the first Children's Commissioner for England and a former President of the BMA who trained as a paediatrician, the author's wealth of experience provides invaluable material on the nature of the problem, why it continues and, equally importantly, how it can be addressed.

The book is divided into three beautifully written sections consisting of seven chapters in total. These cover the importance of ensuring the wellbeing of children, childhood in the UK today, and how to change matters. Each chapter tends to use a common framework in which the reader is provided with the evidence, challenged to identify their role in helping address the situation and some reflective points. A wonderful example is set by the content of the first section, in which differing approaches taken in other countries are discussed along with those responsible for their implementation, why they have been taken and how they could be applied here. The insular approach of politicians, the use of inappropriate performance measures for short-term political expedience, and poor workforce moral is not just limited to the dental sector. The publicly funded dental sector appears to have a remarkable similarity in problems to those in education.

If the scandal in oral health is to be addressed, it will not be through dental reforms alone. However, this is not just about oral health. It is about how we, as a society, look after those who can least look after themselves or whose voice is often ignored. As AynsleyGreen consistently reminds the reader, to do so will require courage, compassion and conviction to stand up and challenge politicians and bureaucrats. These are the very values espoused by Thomas Coram, an individual which the author clearly holds in reverence, and whose work did so much to start to overcome the prejudices towards children in the mid-17th century. This book is a call for today's society to challenge the status quo on the way in which we currently view the issues in childhood today. Those wishing to address them should read this invaluable book. Only then might we see real improvements as a whole as well as in oral health.

By Paul Batchelor 